\title{
Chapter 3 \\ What Do We Know About Community \\ Engagement in Indigenous Education \\ Contexts and How Might This Impact \\ on Pathways into Higher Education?
}

\author{
James A. Smith, Steve Larkin, Dean Yibarbuk, and John Guenther
}

\section{Introduction}

This chapter aims to provide a critical commentary about what is known about 'community engagement' in Indigenous education contexts and how this might impact on pathways into higher education. But first, it is useful to understand the concept of 'community engagement' in a broader sense. Indeed, the term 'community engagement' means many different things to different people. There are various definitions across many disciplines with a general lack of consensus in academic scholarship and grey literature about how community engagement is actually best defined (Ramachandra and Mansor 2014). Likewise, the terms 'community' and 'engagement' are equally contested (Campbell 2008a, b; Dempsey 2010). Whilst some scholars have argued that a logical typology of community engagement involves information sharing, consultation and participation (Johnston 2010), the International Association for Public Participation has outlined five incremental phases of public impact - inform, consult, involve, collaborate and empower (IAP2 2007). Others have offered differing approaches, critiques and tools to unpack what is meant by community engagement (Dempsey 2010; Kotze et al. 2013). A popular

\footnotetext{
J.A. Smith $(\triangle) \cdot D$. Yibarbuk

Office of the Pro Vice-Chancellor - Indigenous Leadership, Charles Darwin University,

Darwin, NT, Australia

e-mail: James.Smith3@cdu.edu.au; Dean.Yibarbuk@cdu.edu.au

S. Larkin

Pro Vice-Chancellor Indigenous Education and Research, University of Newcastle,

Newcastle, NSW, Australia

e-mail: steven.larkin@newcastle.edu.au

J. Guenther

Higher Education and Research Division, Casuarina Campus, Batchelor Institute of Indigenous Tertiary Education, Batchelor, NT, Australia

e-mail: john.guenther@batchelor.edu.au
} 
definition of community engagement adopted by the UN through a consultative process states:

Community Engagement is a two-way process by which the aspirations, concerns, needs and values of citizens and communities are incorporated at all levels and in all sectors in policy development, planning, decision-making, service delivery and assessment; and by which government and other business and civil society organisations involve citizens, clients, communities and other stakeholders in these processes. (United Nations 2005, p. 1)

Generally speaking, 'community engagement finds itself expressed through bottom-up approaches, community ownership, "relevance" to the community, and collaborative approaches' (Campbell and Christie 2008, p. 6). In our view, the challenge of seeking a universal definition of community engagement is unproductive. Nevertheless, an understanding of how community engagement is 'done' is important. Is it something that is 'done' by one entity (such as a government organisation) to another (such as a community) - perhaps with particular 'rules of engagement' with targets in sight? Is it something that is 'done' between two entities (such as a school and parent council) where there is mutual benefit from the 'doing'? Or is it more of a symbiotic process where the boundaries of partnering entities merge as a systemic whole? (see Guenther 2015a, b for a discussion of these concepts).

Yet it is equally important to recognise that it has now become a very popular term in public policy discourses relating to health, education, employment, natural resource management and welfare systems at state, national and international levels. Whilst we recognise that there has been some discussion and theorising about stakeholder engagement in organisational theory scholarship (e.g. see Foster and Jonker 2005; Greenwood and Van Buren 2010), we argue that a more nuanced understanding of the different ways community engagement is conceptualised, theorised and practiced within educational settings in Australia is becoming increasingly important (Johnston 2010). One reason is that the term is now commonly used in a range of research, policy and practice contexts without due consideration of what this means, why this might be important, and how it can be done. Indeed, community engagement is being used somewhat incoherently in strategic plans and frameworks; in ministerial announcements; in government policies; as outputs in service level agreements; as a key requirement during the implementation of various education programs; in ethics proposals; and in commissioned reports and reviews. At present little consideration is given to theoretical and practice implications associated with community engagement. That is, it is mentioned everywhere, but there is a general lack of awareness about what community engagement looks and feels like in reality. In fact, more often than not, it is being used as a catch-all feel-good phrase that gives a sense of purpose, value and connectedness to the work we do.

For some, it is the ethical practice and principles that underpin the way community engagement is enacted that are most important, such as the development of trust, reciprocity and sustainability; for others it is the process, such as acting in a socially just and equitable manner in the way decisions are made; and for others it is about the impact or outcome achieved through community engagement, such as a notable improvement in educational aspiration or achievement. Within an education 
context all of these aspects of community engagement are intimately intertwined. Within an Indigenous education context there is an added cultural and political dimension that also comes into play. Interestingly, much commentary on community engagement fails to acknowledge the social, cultural, political and economic dimensions and their respective impacts. This chapter aims to provide a descriptive account of the way community engagement is currently described, understood and employed in education contexts in Australia. We pay particular attention to the implications this has for promoting Indigenous higher education pathways. To achieve this, we ask five key questions:

1. What do we know about Indigenous community engagement?

2. What do we know about Indigenous community engagement in education contexts?

3. What do we know about community engagement in higher education?

4. What do we know about Indigenous community engagement in higher education?

5. What are the opportunities for improved Indigenous community engagement in Indigenous higher education contexts?

We now discuss each of these questions in turn.

\section{What Do We Know About Indigenous Community Engagement?}

Indigenous community engagement work is happening in a range of contexts both nationally and globally. This includes but is not limited to Indigenous health, education, water and land management and housing sectors (Campbell 2008a, b; Williams 2008; Watts 2012; National Collaborating Centre for Determinants of Health 2013). Generally speaking, recognising the impact of colonisation on both education systems, and respective community engagement approaches, is important (Madden et al. 2013). This has a significant bearing on the way Indigenous and non-Indigenous people interact and exchange information within community engagement contexts (Verran and Christie 2008). Finding alternative community engagement methods that privilege Indigenous epistemologies, ontologies and axiologies are important (Verran and Christie 2008; Madden et al. 2013). We hypothesise that incorporating Indigenous knowledges and practices into the development of Indigenous community engagement tools, and therefore increasing the potential to improve the way in which Indigenous community engagement occurs in practice, will ultimately strengthen Indigenous education outcomes in Australia. Whilst there has been little application of decolonising theories in relation to Indigenous community engagement practices in Australia, there is certainly room for such application. Indeed, understanding how power is negotiated in community engagement activities is fundamental (Head 2007) and is worth of further exploration in Indigenous community 
engagement contexts. Larkin (2015) has examined Indigenous higher education contexts using Critical Race Theory (CRT) to convincingly argue that the centralisation of race and racism; a commitment to challenging the dominant ideology; a commitment to social justice; the centrality of marginalised voices; transdisciplinarity; and interest convergence, are all important considerations. Inherent in these discussions is the concept of power and power relations. The context of engagement is also important. Community engagement in an urban area will take on a different form than engagement in a remote community. Furthermore, outsiders engaging in an inside space need to be self-aware not only about the nature of the context but the nature of assumptions they bring to their role in engagement. We suggest the same general considerations could apply to the way Indigenous community engagement is approached, particularly within education settings.

\section{What Do We Know About Indigenous Community Engagement in Education Contexts?}

In Canada, education policy and curriculum documents encourage the participation of Indigenous community members as a key component of Indigenous education reform (Madden et al. 2013). The implementation of such approaches has resulted in barriers such as unwelcoming schools, professionalisation of classroom teaching, colonised classrooms and unilateral decolonisation being identified as key concerns (Madden et al. 2013). Such research has emphasised the importance of the multiple perspectives of key community stakeholders such as Indigenous students, parents, elders, families, teachers and cultural support workers. There are multiple examples of successful Indigenous community engagement and consultation processes in the education and training sector across Australia. Yet we note that there has been no systematic review and subsequent critical analysis of the success factors of such programs. There has also been minimal evaluation work completed with sufficient theoretical rigour. Whilst we acknowledge this is urgently required, particularly in relation to the benefits of involving Indigenous people and incorporating Indigenous knowledges and practices, it extends beyond the immediate scope of this chapter. Similarly, there are organisations supporting enhanced Indigenous community engagement processes in this space. The NSW Aboriginal Education Consultative Group Inc. and Stronger Smarter Institute are two notable exemplars. We do not provide additional case studies here to illustrate such work, but acknowledge that enhanced profiling of reputable organisations building capacity in Indigenous community engagement work would be useful for practitioners and policy-makers working in Indigenous education and training contexts. Such efforts would help in extending theorising about, and further investments in, Indigenous community engagement in education settings.

Recent research has found that family-strengthening programs are widespread throughout Australia and are frequently used to enhance relationships between 
students, families and schools as a means to improve education outcomes for Indigenous students (Guenther 2014). Further research needs to occur to better understand the longer term outcomes of such work. Whilst the evidence suggests there are many benefits for participants in such programs, the long term community impact of these types of programs, collectively, has not been evaluated. Research conducted by the Cooperative Research Centre for Remote Economic Participation's (CRC-REP) Remote Education Systems project shows definitively that community members see successful schools as those where parents and community members are actively involved in their children's education. What's more, they want to have a greater say in the system's response to schooling in communities (Guenther 2015b; Guenther et al. 2015).

We also know that community engagement is being incorporated into Indigenous education policy contexts in Australia. Using A Share in the Future - Indigenous Education Strategy 2015-2024 as an example, 'engagement' has recently been identified as one of the five major elements to improve Indigenous education outcomes in the Northern Territory (Northern Territory Department of Education 2015a). One goal of 'engagement' outlined in the strategy is that 'parents and communities are engaged with purpose to support their children throughout their learning journey' (Northern Territory Department of Education, p. 9). Yet the target and performance measure relates to the 'proportion of Indigenous students in government schools attending four or more days per week' (Northern Territory Department of Education, p. 11). For us, there is an uneasy disjunction between the goal and the measure and a lack of consideration for the theory of change behind the interventions and their outcomes. Whilst we recognise that attendance is used as a proxy measure for 'student participation' in the Measurement Framework for Australian Schooling in Australia (White 2015), there is a myriad of ways to measure parent and community engagement, such as Indigenous engagement in school governance, levels of parental participation in classroom activities or an increase in student and family aspirations for educational success. These measures are in stark contrast to the desired outcome described in the strategy which focuses on consistent school attendance (which incidentally aligns with a parallel national policy investment known as the Remote School Attendance Strategy). Interestingly, there is no measure in relation to educational achievement which one could argue is a more appropriate measure than school attendance.

Due to the vagueness in the way both 'engagement' and 'community engagement' have been defined in the strategy, the corresponding actions outlined in the implementation plan lack an explicit connection to the goal, target and performance measure. The actions span a single provider girls' engagement program; a community engagement charter to set the expectations to drive respectful and purposeful relationships between schools and communities; and the implementation of a whole system approach to behaviour management and wellbeing in all schools (Northern Territory Department of Education 2015b). Using the development of a Community Engagement Charter as an illustration, the implementation of this action has initially involved mandating school principals to develop a charter within their school. At the timing of writing this chapter, a Family and Community Engagement 
Framework and a Community Engagement Charter template had been distributed to school principals across the Northern Territory (Northern Territory Department of Education 2016). The framework asks a series of questions relating to communication, partnerships to learn, community collaboration, decision-making and participation (Northern Territory Department of Education 2016). It also outlines best practices with respect to strong family and community engagement (Northern Territory Department of Education 2016). Noteworthy is that the Family and Community Engagement Framework developed by the Northern Territory Department of Education is completely disconnected from the territory-wide Remote Engagement and Program Strategy launched only 5 months prior by the Northern Territory Department of Local Government and Community Services (Northern Territory Government 2015).

With respect to the expectation for school principals to develop a Community Engagement Charter, little guidance has been provided to school principals about how community engagement should be negotiated within each remote Indigenous school context; what indicators would be used to measure and monitor the success of the Community Engagement Charter and how they would be held accountable in relation to the charter. Therefore, one can expect that the intensity and nature of community engagement will differ markedly across Northern Territory communities. Activities could potentially range from a one-off school event or open day to an intensive family engagement program or an out-of-hours culture and language program involving information exchange between students, teachers and other community members. The possibilities are endless. We are strong advocates for schools and communities to have the ability to think innovatively and work flexibly to plan and implement community engagement activities. However, it is equally important to understand the purpose and desired outcome of community engagement in Indigenous education settings. Too often this is poorly defined and therefore fails to acknowledge and value an underlying philosophy of community engagement as a means to empower and enable active citizenship.

\section{What Do We Know About Community Engagement in Higher Education?}

Globally, universities have increasingly focused efforts on campus-community engagement and/or university-community engagement (Winter et al. 2006; Dempsey 2010). As Dempsey (2010, p366) comments 'Universities increasingly cast themselves as engaged institutions committed to building collaborative relationships with community-based stakeholders.' Typically, community engagement in higher education is often described as a cluster of activities that include, among others, service learning, programs and research that address specific social, economic and political needs (Bernardo et al. 2012). From an Australian perspective, 
Winter et al. (2006) provide a more detailed analysis suggesting that key dimensions of community engagement in higher education include:

- Teaching and learning

- Curriculum design

- Policies

- Research

- External Relations

- Social and Cultural Engagement

- Partnerships with school and educational providers

- Economic engagement

- Organisation and participation of students

The reality is that community engagement is now a common term used in university-wide strategic plans, with some universities having developed their own specific community engagement strategies and/or established dedicated community engagement roles and responsibilities. There is even a journal dedicated to the topic - Australasian Journal of University-Community Engagement. Interestingly, community engagement is now also used as a common assessment criterion in academic staff promotion processes in many Australian universities. For example, the Charles Darwin University (CDU) academic staff promotion policy indicates that the following factors are assessed in relation to community engagement:

- Significant and valued contributions to a profession, industry partner or to government

- Significant and valued contribution to communities, especially remote, regional and Indigenous communities

- Significant and valued contribution to CDU Equity goals

Whilst these are worthy endeavours, it is unclear how these factors are assessed and who is best positioned to make such assessments. Arguably, community stakeholders would be best positioned to make such assessments but in our experience this is rarely the case.

As Winter et al. (2006, p. 225) explain, 'the local orientation of community engagement is a distinct part of its appeal, offering regional outcomes for communities, opportunities for local students, and projects that are tangible and achievable.' However, community engagement is not necessarily an easy endeavour. Clifford and Petrescu (2012) argue that sustainable university-community engagement involves three intertwined dimensions - internal, external and personal. These factors involve a complex interplay between balancing organisational and community priorities, negotiating power relations and positioning oneself with respect to others. In our experience, these are remarkably similar factors to negotiate in the context of Indigenous community engagement work. One can assume that these dimensions are therefore more pronounced in Indigenous community engagement which focuses on supporting pathways into higher education. 


\title{
What Do We Know About Indigenous Community Engagement with Respect to Pathways into Higher Education?
}

Whilst there are national requirements for universities to report against Indigenous student access, participation, retention and success in higher education; Indigenous involvement in university governance; and Indigenous employment strategies (Kinnane et al. 2014), there is nothing that explicitly requires a broader commitment to Indigenous community engagement. This is problematic. Smith et al. (2015) assert that Indigenous community engagement is a key principle and process that should underpin all program development aimed at supporting Indigenous learners to enter higher education. This was something highlighted regularly during presentations at a national forum held in Darwin in October 2015, which was funded through the Australian Government 2014 Higher Education Participation Program National Priorities Pool. The forum was entitled 'Engagement at the interface: Indigenous pathways and transitions into higher education' and involved bringing together 130 participants (the majority working in Indigenous higher education contexts) from across Australia. Despite a deep interest in the topic of Indigenous community engagement among participants, at this point in time there is very limited published evidence about exactly what Indigenous community engagement can look and feel like with respect to promoting pathways into higher education. This does not imply that there is a lack of action in this space. Quite the contrary, as Kinnane et al. (2014, p. 80) point out,

\begin{abstract}
Many universities collaborate with schools and communities to provide outreach to a greater number of Indigenous students. These programmes are diverse and are making great strides nationally in raising the aspirations of young Aboriginal and Torres Strait Islander students about 'going on to uni.' Valuing and engaging with family and community is a common theme of those universities with successful programmes.
\end{abstract}

Indeed, there is an emerging literature which argues that it is critically important for universities to build trusting and respectful relationships with Indigenous students, their families and the communities to which they belong, to successfully engage in discussions about pathways into higher education (Behrendt et al. 2012; Fredericks et al. 2015). Some Australian universities have invested in Indigenous engagement positions, programs, strategies and frameworks, or have embedded an explicit Indigenous community engagement focus into Reconciliation Action Plans. The scope and functions of these investments varies tremendously, further emphasising that Indigenous community engagement is being conceptualised in different ways within higher education environments in Australia. We argue that the nature, processes and impact of such engagement is important. This is illustrated convincingly in relation to the Community Aspirations Program (CAP-ED) delivered through Central Queensland University:

The project team took the time to develop, maintain and sustain relationships with community members and service providers, and this paid off in their trust and support for the programme, which provided an opportunity to share as it was implemented. Communities were initially hesitant to engage with the project. However, as soon as the project employed 
Indigenous staff who were connected with the communities and had local knowledge, community engagement became much easier. Early engagement fostered additional engagement as the team developed greater knowledge and opened dialogue between the communities and the universities. While it can be challenging to build into projects opportunities for discussion and deep engagement, the efforts pay off through greater opportunities for development, empowerment and change. By developing deep relationships with Elders and community members, the CAP-ED team designed a programme with community ownership of both the process and the outcomes (Fredericks et al. 2015, p. 61).

The concepts raised by Fredericks et al. (2015) highlight important considerations when engaging Indigenous students and families in discussion about higher education. A commitment of time and sustained engagement is a central feature. Employment of local Indigenous staff is equally important. These are key learnings to consider when investing in Indigenous community engagement in higher education contexts. However, at this point in time, there is a paucity of quality research and evaluation data to make firm evidence-based recommendations about what works best and why and in what circumstances (Frawley et al. 2015). Further investments in comprehensive and rigorous program evaluations and collaborative research approaches would help to grow a stronger evidence base in this regard.

\section{What Are the Opportunities for Improved Indigenous Community Engagement in Indigenous Higher Education Contexts?}

The aforementioned discussion has led us to identify four major opportunities for improving Indigenous community engagement in higher education. These include:

1. Redefining community engagement from Indigenous standpoints

2. Appropriately resourcing Indigenous community engagement activities

3. Continuing to build an evidence base to learn from recent Indigenous community engagement investments

4. Move beyond the rhetorical language used in many policy documents and frameworks

Each of these focus areas is discussed briefly below.

\section{Redefining Community Engagement from Indigenous Standpoints}

If we want to see improvements and further investment in the area of Indigenous community engagement in higher education, then we need to place greater attention on the potential contribution of Indigenous knowledges and practices. This involves a number of key elements. Firstly, a heightened level of theorising about Indigenous community engagement would be beneficial. This could include the incorporation 
of theoretical approaches such as Indigenous Standpoint Theory; Whiteness Theory or Critical Race Theory. Noting the outstanding work already done by Indigenous scholars in this field both in Australia (e.g. Moreton-Robinson 2006a, b; Arbon 2008; Ford 2010; Nakata et al. 2012) and internationally (e.g. Bishop 2011; Chilisa 2012), we hypothesise this would see a fundamental shift in the way Indigenous community engagement is approached by universities. It would see a shift away from a Eurocentric worldview, to a paradigm more closely aligned to Indigenous epistemologies and ontologies. Secondly, if we start to view Indigenous community engagement in this way, the probability of pursuing community engagement that is framed in a more culturally respectful and responsive way is much more likely. As a consequence, we may find that the doing of engagement takes on a different dynamic, such that those who were once the targets of engagement become the initiators of engagement. This would be consistent with both ways learning approaches frequently advocated in the Indigenous education space (White 2015).

\section{Appropriately Resourcing Indigenous Community Engagement Activities}

A significant challenge faced in many universities in Australia is ensuring that a sufficient quantum of funds is allocated to pursue quality community engagement work. Given that emerging evidence suggests that time, sustained engagement and whole-of-community engagement approaches are important elements in what Indigenous community engagement constitutes (Fredericks et al. 2015; Smith et al. 2015), we know that additional resources are usually required in comparison to mainstream university-community engagement contexts. In many universities, this includes a commitment to increase a core investment in financial and human resources, which contrasts the more frequently accessed time-limited nationally competitive funding sources. Within a tight fiscal environment, the realisation that appropriate resourcing is a key factor is not always well received. However, if we want to see improvements in Indigenous education outcomes, then it is a necessary non-negotiable step. Within the context of regional and remote Indigenous community engagement the need for additional resourcing becomes even more critical. Factors such as travel, accommodation, inclement weather, sorry business, use of interpreters, Indigenous leadership and governance capacity, and remuneration for Indigenous expertise and cultural brokerage (in the form of sitting fees or employment of local community members) frequently come into play. There is currently insufficient evidence about what the real costs are, in relation to human and financial capital, to do this well. Similarly, there has been a lack of investment in professional development, education and training by governments and other institutions (such as universities) to enhance Indigenous community engagement efforts. Given that community engagement has both theoretical and practice elements that are not necessarily well understood, respective outcomes for the Indigenous communities we wish to engage are often suboptimal. 


\section{Continuing to Build an Evidence Base to Learn from Recent Indigenous Community Engagement Investments}

We have pointed towards an emerging evidence base about Indigenous community engagement in higher education in Australia. But we have also explained that additional collaborative research and more sophisticated forms of evaluation and monitoring are required (Smith et al. 2015). The recent national forum on Indigenous pathways and transitions into higher education, coupled with recent investments in Indigenous higher education aspiration building programs through the federally funded Higher Education Participation Program, indicate that there is a groundswell of work happening in this area. Therefore, there is great potential to build a substantial evidence base about Indigenous community engagement relatively quickly. We argue that this should be a key research and policy reform priority within the Indigenous higher education space.

\section{Move Beyond the Rhetorical Language Used in Many Policy Documents and Frameworks}

As mentioned in the Introduction, and later illustrated using a Northern Territory Indigenous education policy example, the way in which Indigenous community engagement is conceptualised in policy documents and strategic frameworks needs be critically analysed and challenged. At present, there is a high degree of ambiguity in such documents, which ultimately leads to a lack of accountability with respect to improving Indigenous education outcomes. Within higher education contexts, this means being explicit about how Indigenous community engagement is defined, who defines it and who does it. We argue that the foundation for such work is best developed in collaboration with key community stakeholders including Indigenous Elders, students, their families, community-based organisations and where relevant their employers or schools. To do this with integrity requires an approach where the assumptions of academia, and those of context in which engagement is done, are unpacked together. There is considerable opportunity for non-Indigenous and Indigenous scholars to work together on this, building theories and practical applications at the 'cultural interface' (Nakata 2007) which will assist in the development of community actions that truly meet the needs and aspirations of Indigenous people. This will, however, require careful negotiation. Community engagement is occasionally perceived as an outcome rather than a process to achieve an outcome. This has led to some Indigenous communities becoming confused and perhaps disillusioned by the purpose of such engagement. As emphasised earlier, this is further exacerbated by the lack of investment in professional development activities about what good community engagement looks and feels like. 


\section{Conclusion}

In this chapter, we have incrementally examined the concept of community engagement in relation to (a) Indigenous community engagement; (b) Indigenous community engagement in education; (c) community engagement in higher education and (d) Indigenous community engagement in higher education. This descriptive analysis has outlined the various strengths and weaknesses of such approaches based on current scholarship. In doing so, we highlight that a critical analysis of existing Indigenous community engagement programs in education settings is needed, including more theoretically rigorous and more complex and comprehensive evaluation processes. We have also used existing policy discourses to illustrate some of the challenges educators face when attempting to make transitions from policy into practice with respect to Indigenous community engagement. We then briefly discussed some of the opportunities for improving Indigenous community engagement in the higher education sector. This includes redefining community engagement from Indigenous standpoints; appropriately resourcing Indigenous community engagement activities; continuing to build an evidence base to learn from recent Indigenous community engagement investments and to move beyond the rhetorical language used in many policy documents and frameworks. We argue that if steps are taken to improve the quality and quantum of Indigenous community engagement work occurring in the higher education sector in Australia in this way, then we are on a strong path for improving Indigenous pathways and transitions into university.

\section{References}

Arbon, V. (2008). Arlathirnda Ngurkarnda Ityirnda: Being-knowing-doing, de-colonising indigenous tertiary education. Teneriffe: Post Press.

Bernardo, M., Butcher, J., \& Howard, P. (2012). An international comparison of community engagement in higher education. International Journal of Educational Development, 32(1), 187-192.

Behrendt, L., Larkin, S., Griew, R., \& Kelley, P. (2012). Review of higher education access and outcomes for aboriginal and Torres Strait Islander people: Final report. Canberra: Department of Industry, Innovation, Science, Research and Tertiary Education.

Bishop, R. (2011). Freeing ourselves. Rotterdam: Sense Publishers.

Campbell, D. (2008a). Community engagement in a health research project at Gapuwiyak. In M. Campbell \& M. Christie (Eds.), Indigenous community engagement at Charles Darwin University. A research project funded by the Office of Pro Vice Chancellor, Community and Access and supported through the School for Social and Policy Research. Darwin: Uniprint.

Campbell, M. (2008b). Is it the community, or is it something else (that we engage with)? In M. Campbell \& M. Christie (Eds.), Indigenous community engagement at Charles Darwin University. A research project funded by the Office of Pro Vice Chancellor, Community and Access and supported through the School for Social and Policy Research. Darwin: Uniprint.

Campbell, M., \& Christie, M. (2008). Indigenous community engagement at Charles Darwin University. A research project funded by the Office of Pro Vice Chancellor, Community and Access and supported through the school for social and policy research. Darwin: Uniprint.

Chilisa, B. (2012). Indigenous research methodologies. Los Angeles: SAGE.

Clifford, D., \& Petrescu, C. (2012). The keys to university-community engagement sustainability. Nonprofit Management and Leadership, 23(1), 77-91. 
Dempsey, S. (2010). Critiquing community engagement. Management Communication Quarterly, 24(3), 359-390.

Ford, P. L. (2010). Aboriginal knowledge narratives and country: Marri kunkimba putj putj marrideyan. Brisbane: Post Pressed.

Foster, D., \& Jonker, J. (2005). Stakeholder relationships: The dialogue of engagement. Corporate Governance: The International Journal of Business in Society, 5(5), 50-59.

Frawley, J., Smith, J., \& Larkin, S. (2015). Beyond Bradley and Behrendt: Building a stronger evidence-base about indigenous pathways and transitions into higher education. Learning Communities: International Journal of Learning in Social Contexts, 17(1), 8-11.

Fredericks, B., Lamey, T., Mikecz, M., \& Santamara, F. (2015). Enabling people to 'see what they can be': The community aspirations program (CAP-ED). Learning Communities: International Journal of Learning in Social Contexts, 17(1), 54-63.

Greenwood, M., \& Van Buren, H. (2010). Trust and stakeholder theory: Trustworthiness in the organisation-stakeholder relationship. Journal of Business Ethics, 95(3), 425-438.

Guenther, J. (2014). Families and Schools Together (FAST) at Gillen primary school: The sustained impact of a family-strengthening program. CRC-REP research report CR002. Ninti One Limited, Alice Springs.

Guenther, J. (2015a). Community engagement in remote schools: Just who is engaged and what for? Paper presented at the Remote Education Systems Lecture Series, North Australian Research Unit, Darwin. Lecture \#10, 18 November 2015. Retrieved from https://www.academia. edu/18551981/Community_engagement_in_remote_schools_Just_who_is_engaged_and_ what_for

Guenther, J. (2015b). Overview of remote education systems qualitative results. CRC-REP Working paper. CW025, Ninti One Limited. Retrieved from http://www.crc-rep.com.au/ resource/CW025_RemoteEducationSystemsQualitativeResults.pdf

Guenther, J., Disbray, S., \& Osborne, S. (2015). Building on 'Red Dirt' perspectives: What counts as important for remote education? Australian Journal of Indigenous Education, 44(2), 194206. doi:http://dx.doi.org/10.1017/jie.2015.20

Head, B. (2007). Community engagement: Participation on whose terms? Australian Journal of Political Science, 42(3), 441-454.

IAP2. (2007). IAP2 Spectrum of public participation. International Association for Public Participation.

Johnston, K. (2010). Community engagement: Exploring a relational approach to consultation and collaborative practice in Australia. Journal of Promotion Management, 16(1-2), 217-234.

Kinnane, S., Wilks, J., Wilson, K., Hughes, T., \& Thomas, S. (2014). 'Can't be what you can't see': The transition of aboriginal and Torres Strait Islander students into higher education: Final report 2014. Sydney: Office for Learning and Teaching.

Kotze, M., Seedat, M., Suffla, S., \& Kramer, S. (2013). Community conversations as community engagement: Hosts' reflections. South African Journal of Psychology, 43(4), 494-505.

Larkin, S. (2015). Critical race theory and indigenous higher education: Towards a remaking of the University. In H. Huijser, R. Ober, S. O’Sullivan, E. McRae-Williams, \& R. Elvin (Eds.), Finding common ground: Narratives, provocations, and reflections from the 40-year celebration of Batchelor Institute. Batchelor: Batchelor Press.

Madden, B., Higgins, M., \& Korteweg, L. (2013). 'Role models can't just be on posters': Remembering barriers to indigenous community engagement. Canadian Journal of Education, $36(2), 212-247$.

Moreton-Robinson, A. (2006a). Whiteness matters: Implications of talkin' up to the white woman. Australian Feminist Studies., 21(50), 245-256.

Moreton-Robinson, A. (2006b). Towards a new research agenda? Foucault, whiteness and indigenous sovereignty. Journal of Sociology, 42(4), 383-395.

Nakata, M. (2007). The cultural interface. Australian Journal of Indigenous Education, 36(Supplement), 7-14.

Nakata, M., Nakata, V., Keech, S., \& Bolt, R. (2012). Decolonial goals and pedagogies for indigenous studies. Decolonization: Indigeneity, Education \& Society, 1(1), 120-140.

National Collaborating Centre for Determinants of Health. (2013). A guide to community engagement frameworks for action on the social determinants of health and health equity. Antigonish: National Collaborating Centre for Determinants of Health, St. Francis Xavier University. 
Northern Territory Department of Education. (2015a). A share in the future-Indigenous education strategy 2015-2024. Darwin: Northern Territory Government.

Northern Territory Department of Education. (2015b). A share in the future - Indigenous education strategy 2015-2024: Implementation plan 2015-2017. Darwin: Northern Territory Government.

Northern Territory Department of Education. (2016). Family and community engagement framework: A guide for families, communities, carers and Northern Territory Government schools. Darwin: Northern Territory Government.

Northern Territory Government. (2015). Remote engagement and coordination strategy. Darwin: Northern Territory Government.

Ramachandra, A., \& Mansor, N. (2014). Sustainability of community engagement - In the hands of stakeholders? Education + Training, 56(7), 588-598.

Smith, J., Larkin, S., \& Trinidad, S. (2015). Participation in higher education in Australia among under-represented groups: What can we learn from the higher education participation program to better support indigenous learners? Learning Communities: International Journal of Learning in Social Contexts, 17(1), 12-28.

United Nations. (2005, August 15-17). Brisbane Declaration - United Nations Charter on Community Engagement. International Conference on Engaging in Communities, Brisbane.

Verran, H., \& Christie, M. (2008). Engaging with Australian indigenous knowledge systems. In M. Campbell \& M. Christie (Eds.), Indigenous community engagement at Charles Darwin University. A research project funded by the Office of Pro Vice Chancellor, Community and Access and supported through the School for Social and Policy Research. Darwin: Uniprint.

Watts, L. (2012). Effective methods of engagement between water planners and Indigenous stakeholders: Indigenous engagement framework. Prepared by Centrefarm Aboriginal Horticulture Ltd for the Department of Natural Resources, Environment, The Arts and Sport, Alice Springs.

White, L. (2015). Finding the common ground with indigenous and Western knowledge systems and seeking the common good for all present and future Australians - Where is the common ground if we are going to find it. In H. Huijser, R. Ober, S. O'Sullivan, E. McRae-Williams, \& R. Elvin (Eds.), Finding common ground: Narratives, provocations, and reflections from the 40-year celebration of Batchelor Institute. Batchelor: Batchelor Press.

Williams, G. (2008). Djelk Rangers and Charles Darwin University: What can we learn about Indigenous community engagement. In M. Campbell \& M. Christie (Eds.), Indigenous community engagement at Charles Darwin University. A research project funded by the Office of Pro Vice Chancellor, Community and Access and supported through the School for Social and Policy Research. Darwin: Uniprint.

Winter, A., Wiseman, J., \& Muirhead, B. (2006). University-community engagement in Australia: Practice, policy and public good. Education, Citizenship and Social Justice, 1(3), 211-230.

Open Access This chapter is licensed under the terms of the Creative Commons Attribution 4.0 International License (http://creativecommons.org/licenses/by/4.0/), which permits use, sharing, adaptation, distribution and reproduction in any medium or format, as long as you give appropriate credit to the original author(s) and the source, provide a link to the Creative Commons license and indicate if changes were made.

The images or other third party material in this chapter are included in the chapter's Creative Commons license, unless indicated otherwise in a credit line to the material. If material is not included in the chapter's Creative Commons license and your intended use is not permitted by statutory regulation or exceeds the permitted use, you will need to obtain permission directly from the copyright holder. 